Journal of Advanced Research in Fluid Mechanics and Thermal Sciences

Journal homepage: www.akademiabaru.com/arfmts.html ISSN: 2289-7879

\title{
Thermoacoustic Refrigerators and Heat Pumps: New Insights for A High Performance
}

\author{
Mahmoud A. Alamir ${ }^{1,}{ }^{*}$, Nor Azwadi Che Sidik ${ }^{2}$ \\ College of Science and Engineering, Flinders University, Clovelly Park, Adelaide, SA 5042, Australia \\ 2 Malaysia -Japan International Institute of Technology (MJIIT), University Teknologi Malaysia, Jalan Sultan Yahya Petra, 54100 Kuala Lumpur, \\ Malaysia
}

\section{ARTICLE INFO ABSTRACT}

\section{Article history:}

Received 11 August 2020

Received in revised form 20 October 2020

Accepted 25 October 2020

Available online 30 November 2020

\begin{abstract}
Thermoacoustic refrigerators and heat pumps are considered one of the important emerging green technologies. They are based on the use of acoustic pressure waves to supply cooling or heating effects. The oscillating gas interaction with a solid wall called the stack generates thermoacoustic effects. This study presents the effects of the operating conditions and geometric parameters on the temperature difference across the stack and the coefficient of performance of a thermoacoustic heat pump at different cooling loads. The design steps of these systems were also demonstrated. Theoretical study of the operation conditions and geometric parameters was presented using "DeltaEC". The results showed that higher harmonics are less desirable for thermoacoustic phenomena as they lower the temperature difference across the stack. Further insights into the effects of amplitude pressure, mean pressure and stack geometries were also demonstrated. This study helps to establish the concepts and design steps for thermoacoustic refrigerators and heat pumps.
\end{abstract}

Keywords:

Refrigeration; Thermoacoustics;

Temperature difference; Performance

\section{Introduction}

The world faces many environmental, health and energy problems nowadays. Refrigeration and heat pumping technologies have increasing importance; to the extent that they are irreplaceable in many areas: industrial, medical, gas liquefaction processes for fuel used in aircraft, missiles, ships and other vital areas of everyday life. Cooling technology has evolved in recent decades to overcome the problem of refrigerant which is harmful to the environment and to take advantage of any lost or renewable source of energy to overcome the problems stated. Thermoacoustics is an emerging green technology that has growing application fields. Thermoacoustic refrigerators are based on the relation between temperature and pressure variations on the longitudinal acoustic wave.

\footnotetext{
* Corresponding author.

E-mail address: mahmoud.alamir@flinders.edu.au
}

https://doi.org/10.37934/arfmts.78.1.146156 
Thermoacoustic heat pumping devices and refrigerators make use of acoustic power to pump heat from a low-temperature sink to a high-temperature source [1]. They consist of the resonator, stack, two heat exchangers, working fluid and acoustic driver (e.g. loudspeaker) which is fed with the signal from the wave generator and the amplifier as shown in Figure 1. Bryton cycle is the basic working principle, where thermoacoustic cycle compressions and expansions occur by the acoustic driver that oscillates forward and backwards causing the changes in pressure. Two heat exchangers were also encountered as did Bryton cycles.

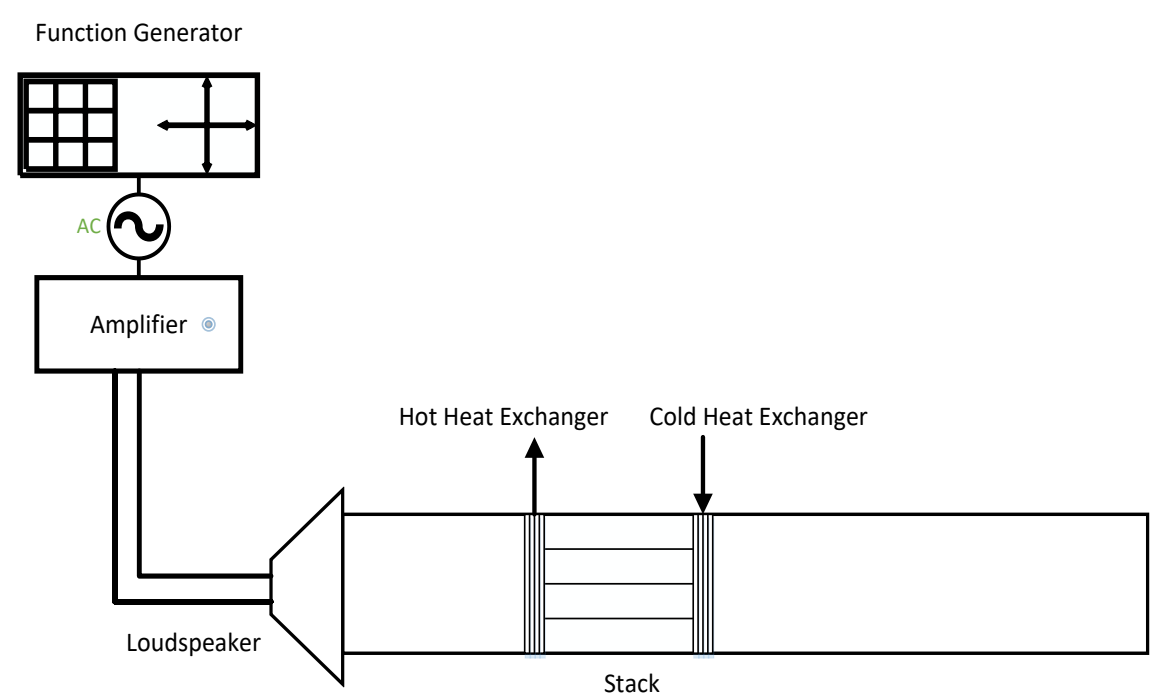

Fig. 1. Schematic diagram of a thermoacoustic refrigerator showing its components

Great efforts for improving thermoacoustic systems were done. Researchers tried to generalize the design and optimization steps. For example, Wetzel and Herman [2] developed a design algorithm for acoustically-driven thermoacoustic heat pumps, the consumed electric power based on this algorithm is consumed in the stack and the heat exchangers and the resonator according to the following equation.

$\dot{W}_{\text {tot }}=\dot{W}_{s}+\dot{W}_{\text {res }}+\dot{W}_{\text {hex }}$

Babaei and Siddiqui [3] developed a comprehensive systematic procedure for the design and optimization of thermoacoustic systems by applying the simplified linear thermoacoustic model. Tijani et al., [4] constructed a loudspeaker driven refrigerator that was well operated and a low temperature of $-65^{\circ} \mathrm{C}$ was reached based on his design algorithm. However, problems can be found with these optimization algorithms. For example, they could disregard optimising important operating conditions such as the resonance frequency and not compromise temperature difference and performance [5-8]. Other problems include the theoretical background used as the basic linear theory equations developed and are usually used incorrectly. They can be different from the equations of real systems with different components. Other problems could be the incapability to track real temperature variations inside the refrigerator [9].

DeltaEC is a computer program that can calculate the performance of thermoacoustic equipment, or can help the user to design equipment for the desired performance. The Los Alamos group has developed such a program [10]. Many researchers have used it to simulate their work; DeltaEC was used as verification for a design and optimization procedure algorithm for thermoacoustic systems by Babaei and Siddiqui [3]. This program was also used by Tijani et al., [4] to simulate his work. Arafa 
et al., [11] investigated the effect of the mean pressure and stack geometry on the engine performance by using DeltaEC; they demonstrated the importance of these parameters and their effect on the engine performance.

This work presents the important design parameters of thermoacoustic refrigerators and heat pumps. The effects of changing the operating conditions and geometric parameters on the temperature difference across the stack are also theoretically and physically demonstrated using the free simulation software DeltaEC. Thermoacoustic technologies could be an alternative to other technologies that can have severe environmental impacts [12-26]. Finding viable applications of thermoacoustic engines and refrigerators has turned out to be quite challenging [27]. Many teams tried different designs and optimization methods for 20 years towards remarkable commercial success, but then traditional energy-conversion technologies were found to do the same job at lower costs, smaller sizes or with some other key advantages. This study provides guidelines for increasing the performance of thermoacoustic refrigerators. While other travelling wave thermoacoustic heat pump designs could have higher performance, a standing wave thermoacoustic heat pump design was used to allow more convenient theoretical and physical understanding of the problem. This could help establish a deeper understanding of the effect of different geometric parameters and operating conditions on the performance of heat pumps and refrigerators.

\section{Theoretical Analysis}

The thermoacoustic effect occurs inside the walls of the stack so there is a thermal contact. The thermal penetration depth $\delta_{k}$ is the thickness of the layer of the gas where heat can diffuse through during half a cycle of oscillations.

$\delta_{k}=\sqrt{\frac{2 K}{\omega \rho_{m} C_{p}}}$

Viscous penetration depth $\delta_{v}$ is the thickness of the layer where the viscosity effect is effective near the boundaries of the stack walls.

$\delta_{v}=\sqrt{\frac{2 \mu}{\omega \rho_{m}}}=\sqrt{\frac{2 v}{\omega}}$

There are many thermoacoustic refrigeration design parameters to be interpreted in thermoacoustic equations, which are nineteen parameters, so a dimensionless analysis of thermoacoustic design parameters was done by Wetzel and Herman [2]. The stack length, position and pore size affect the overall obtained cooling load and the required input acoustic power as shown in Eq. (4) and Eq. (5) for the dimensionless cooling power $\dot{Q}_{c n}$ and the dimensionless acoustic power $\dot{W}_{n}$ respectively.

$$
\begin{aligned}
& \dot{Q}_{c n}=-\frac{\delta_{k n} D^{2} \sin \left(2 X_{s n}\right)}{8 \gamma \Lambda(1+\sigma)}\left[\frac{\Delta T_{m n} \tan \left(X_{s n}\right)}{L_{s n} B(\gamma-1)} \frac{1+\sqrt{\sigma}+\sigma}{1+\sqrt{\sigma}}-\left(1+\sqrt{\sigma}-\sqrt{\sigma} \delta_{k n}\right)\right] \\
& \dot{W}_{n}=\frac{\delta_{k n} L_{s n} D^{2}}{4 \gamma}(\gamma-1) B \cos \left(X_{s n}\right)^{2}\left(\frac{\Delta T_{m n} \tan \left(X_{s n}\right)}{\Lambda L_{s n} B(\gamma-1)(1+\sqrt{\sigma})}-1\right)-\frac{\delta_{k n} L_{s n} D^{2}}{4 \gamma} \frac{\sqrt{\sigma} \sin \left(X_{s n}\right)^{2}}{\Lambda B}
\end{aligned}
$$


where

$\Lambda=1-\frac{\delta_{\mathrm{v}}}{y_{0}}+\frac{\delta_{\mathrm{v}}{ }^{2}}{2 y_{0}^{2}}$

The coefficient of performance COP and the Carnot coefficient of performance COPC and the relative coefficient of performance COPR can be defined as follows

$$
\begin{aligned}
& C O P=\frac{\dot{Q}_{C}}{\dot{W}}=\frac{\dot{Q}_{c n}}{\dot{W}_{n}} \\
& C O P C=\frac{T_{C}}{T_{H}-T_{C}} \\
& \text { COPR }=\frac{C O P}{C O P C}
\end{aligned}
$$

\section{Mathematical Model}

The model was built to provide a better understanding of the operating conditions and geometric parameters, and their effects on the temperature difference across the stack, and the coefficient of performance for the thermoacoustic heat pump at different cooling loads. The operating conditions and geometric parameters will be investigated by DeltaEC software to do the code used for simulating the design. The study will consider a constant cooling load and calculate the incoming acoustic power that varies with changing conditions.

A design of thermoacoustic refrigerator required to give a cooling power of $5 \mathrm{~W}$, desired temperature difference, $\Delta T_{m}=15 \mathrm{~K}$, mean operating temperature, $T_{m}=300 \mathrm{~K}$, mean pressure, $P_{m}=2$ bar, pressure amplitude, $P_{0}=2 \mathrm{kPa}$ and frequency, $f=500 \mathrm{~Hz}$ using helium will be presented depending on the sequence shown in Figure 2 for design. The results of the different thermoacoustic refrigerator design elements were simulated through DeltaEC program as shown in Figure 3. DeltaEC was used to show the effects of the operation conditions and geometric parameters at different cooling loads by using inner and outer plot features available in the program. In this theoretical study, it is shown that the different operation and geometric parameters can affect the performance and the temperature difference across the stack. The detailed code can be found through the previous link as well. The optimum operating conditions and geometric parameters were chosen to put into consideration both the performance and the temperature difference and then build-up for the next investigation. 


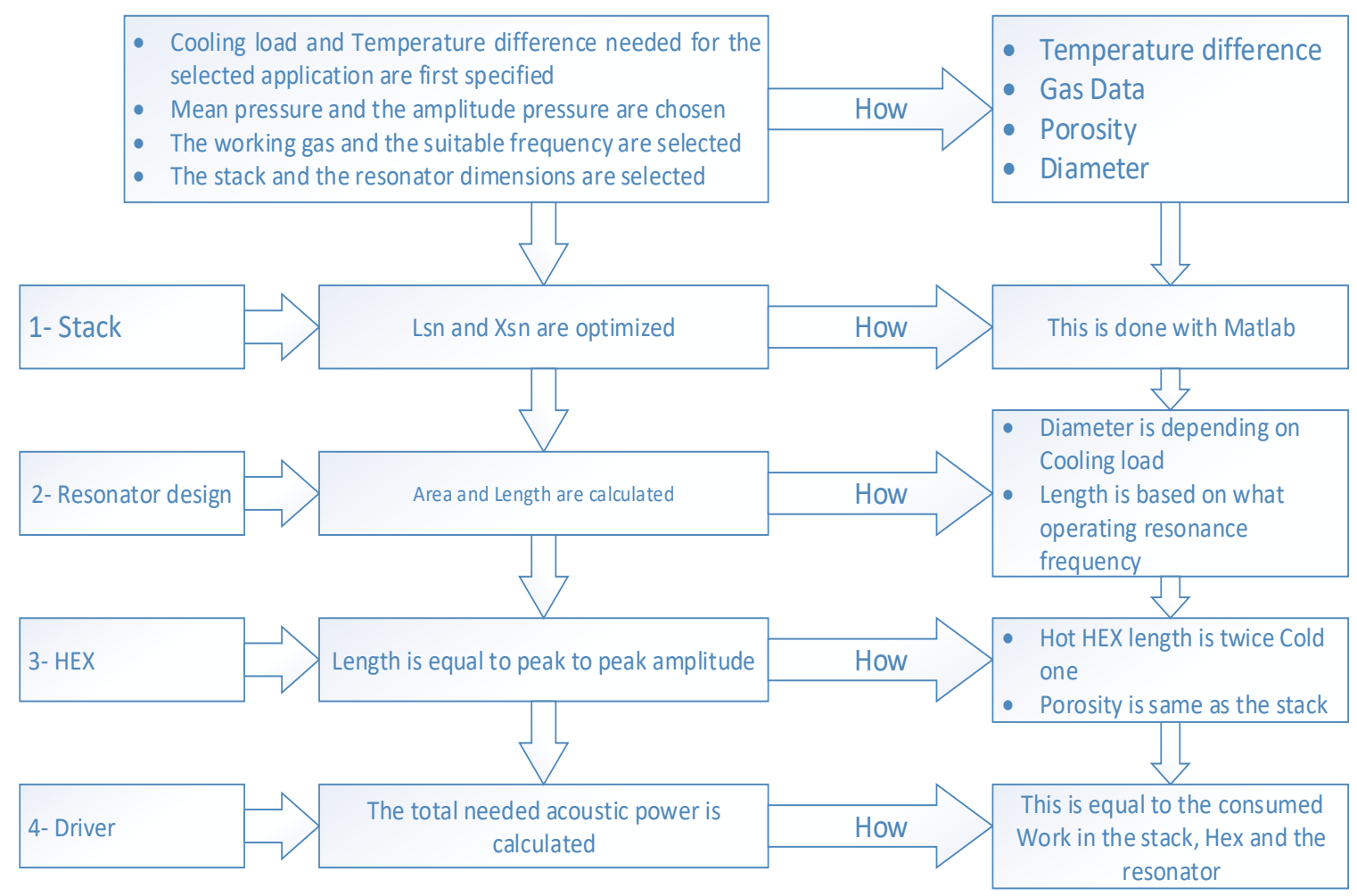

Fig. 2. Design steps for a $5 \mathrm{~kW}$ thermoacoustic refrigerator. Each row represents each step's design element and how it is optimized

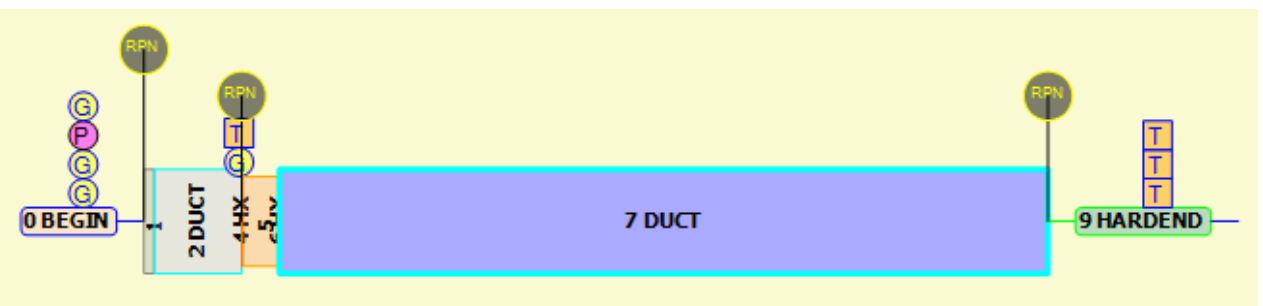

Fig. 3. DELTAEC theoretical model

\section{Results and Discussions}

\subsection{The Frequency Effect}

There are many multiples of the fundamental harmonic resonance frequency. The first resonance frequency as calculated from DELTAEC for the theoretical model was $473.73 \mathrm{~Hz}$ and higher-order frequencies were $953.42 \mathrm{~Hz}$ and $1475.4 \mathrm{~Hz}$.

\subsubsection{The effect of resonance frequency on the temperature flow}

The temperature flow through the resonator shows that higher harmonics are less desirable on the thermoacoustic phenomena as they lower the temperature difference across the stack, and this decrease is due to the non-good prediction of the good stack position and also due to lower acoustic pressure values, the temperature flow through the resonator is well-demonstrated Figure 4, showing a temperature difference of 31,27 and $8.62 \mathrm{~K}$ for the three harmonics respectively. 


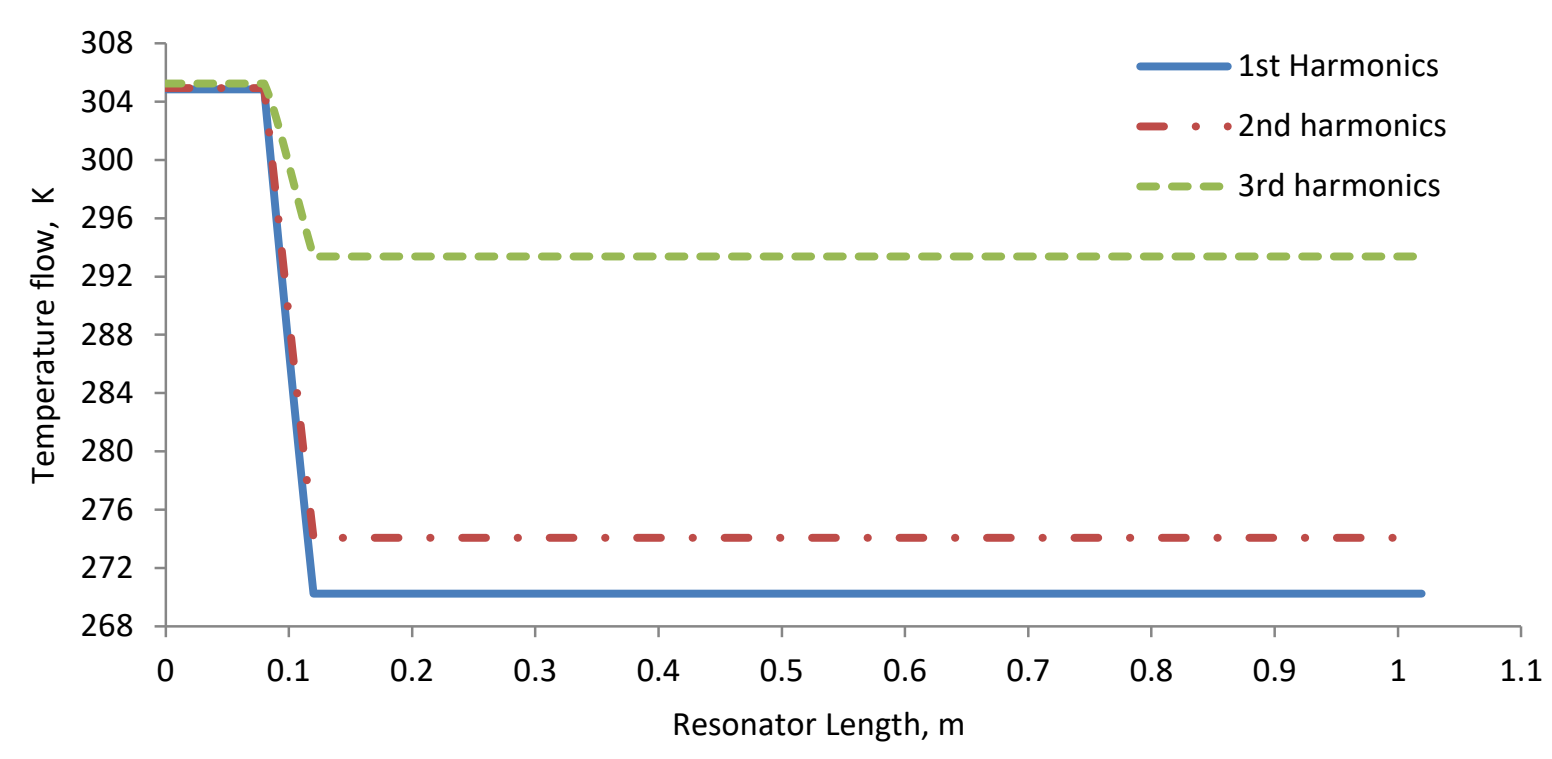

Fig. 4. The temperature flow versus the resonator length for different frequency harmonics

\subsubsection{The effect of resonance frequency on the power flow}

To give a constant cooling load of $5 \mathrm{~W}$, higher harmonics consume more acoustic power and hence higher harmonics have lower COP values. Calculated COP gives values of 1.32, 0.76 and 0.493 for the three harmonics respectively as shown in Figure 5, so the first resonance frequency is desirable for the high performance and high-temperature difference [8].

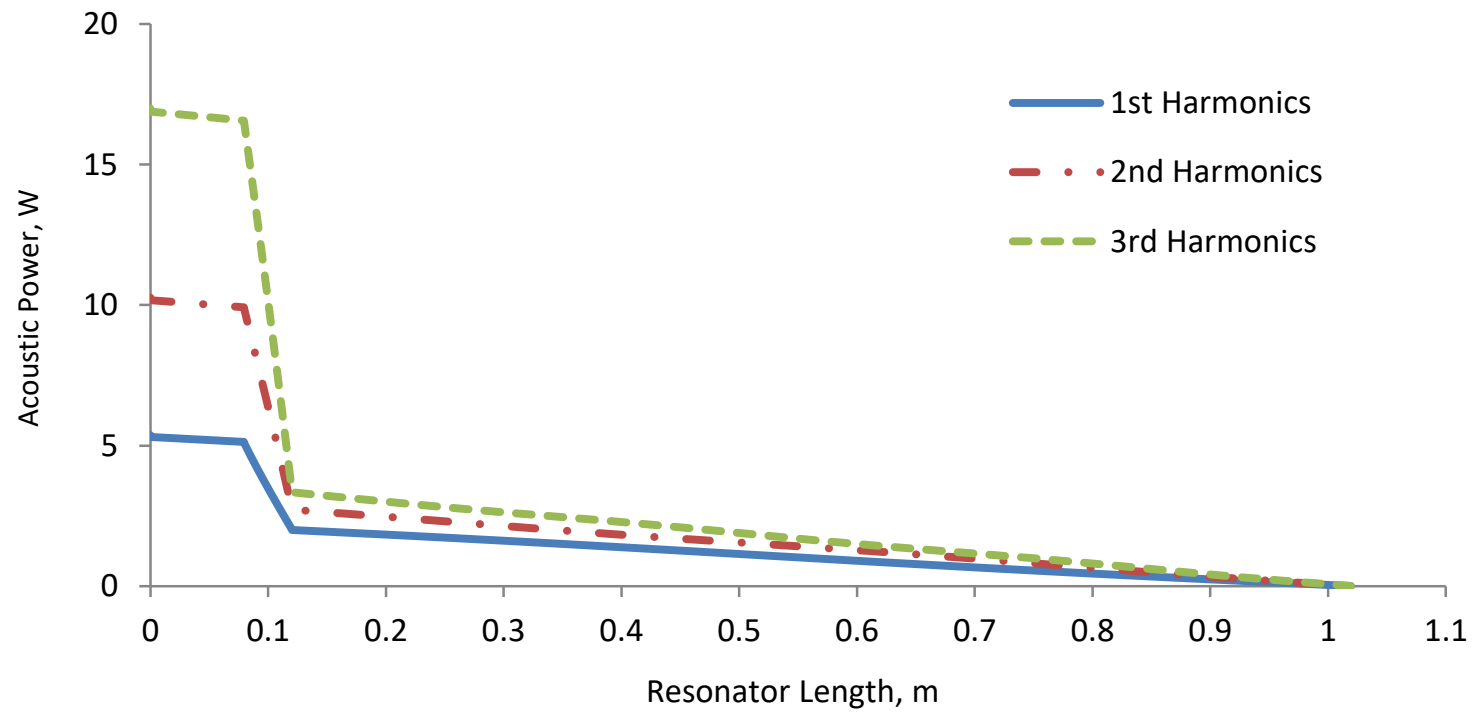

Fig. 5. The acoustic power flow across the resonator for different harmonics

\subsection{Mean Pressure Analysis}

Figure 6 demonstrates the temperature difference against mean pressure; increasing mean pressure decreases the temperature difference. This phenomenon happens due to the weakness of the pressure amplitude [8]. 


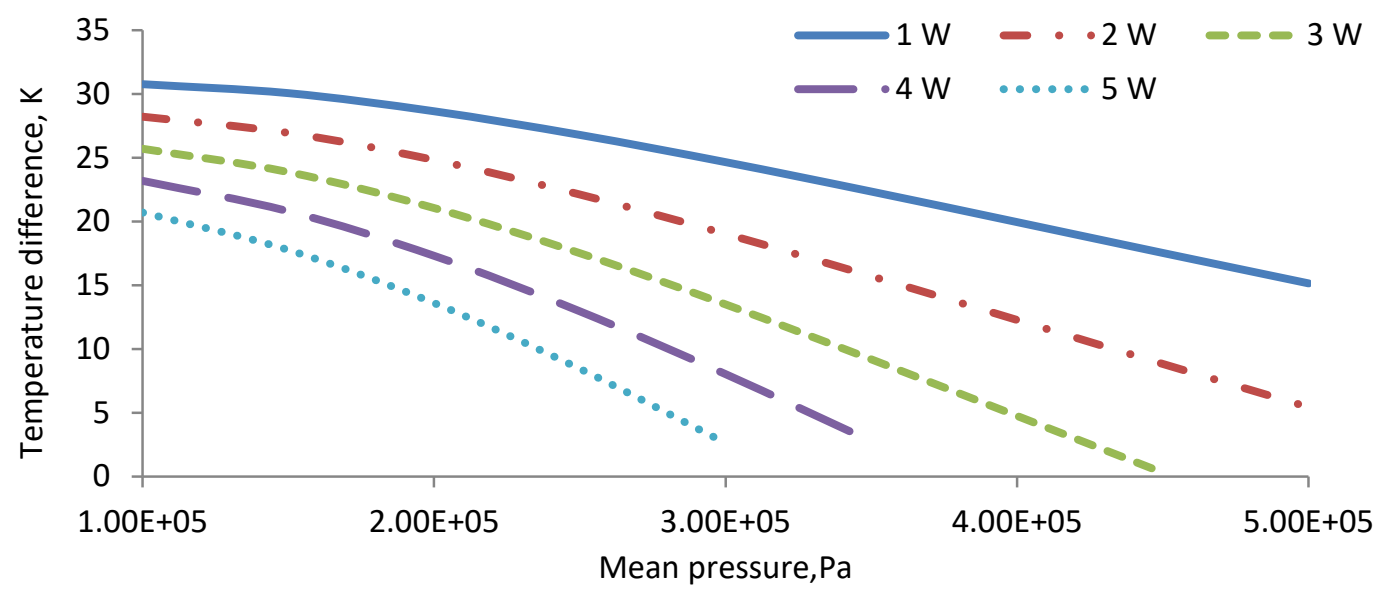

Fig. 6. The temperature difference vs. mean pressure for cooling loads $(1,2,3,4$, and 5 Watts)

\subsection{Pressure Amplitude Analysis}

The temperature difference begins with a low value due to the weakness of pressure amplitude as shown in Figure 7. Then, the increase of amplitude pressure increases the temperature difference until it reaches a maximum value and then decreases as a lot of gas parcels do not interact with the plate due to reduction in thermal penetration value.

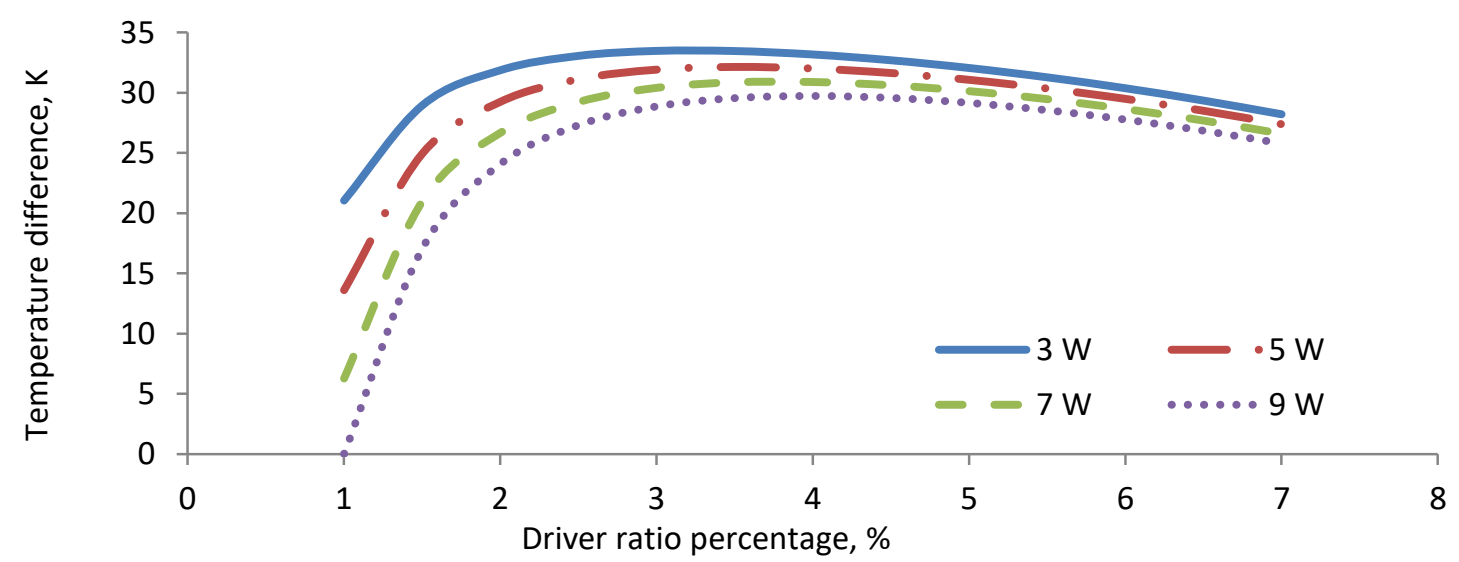

Fig. 7. The temperature difference vs. driver ratio at different cooling loads $(3,5,7,9$ Watts)

\subsection{Stack Plate to Plate Spacing}

The temperature difference will increase when the plate space increases to a maximum value where there are more viscous losses as shown in Figure 8. Then, these losses decrease with the increase of spacing and the weak thermal contact has then the major effect and the temperature difference decreases again [8]. 


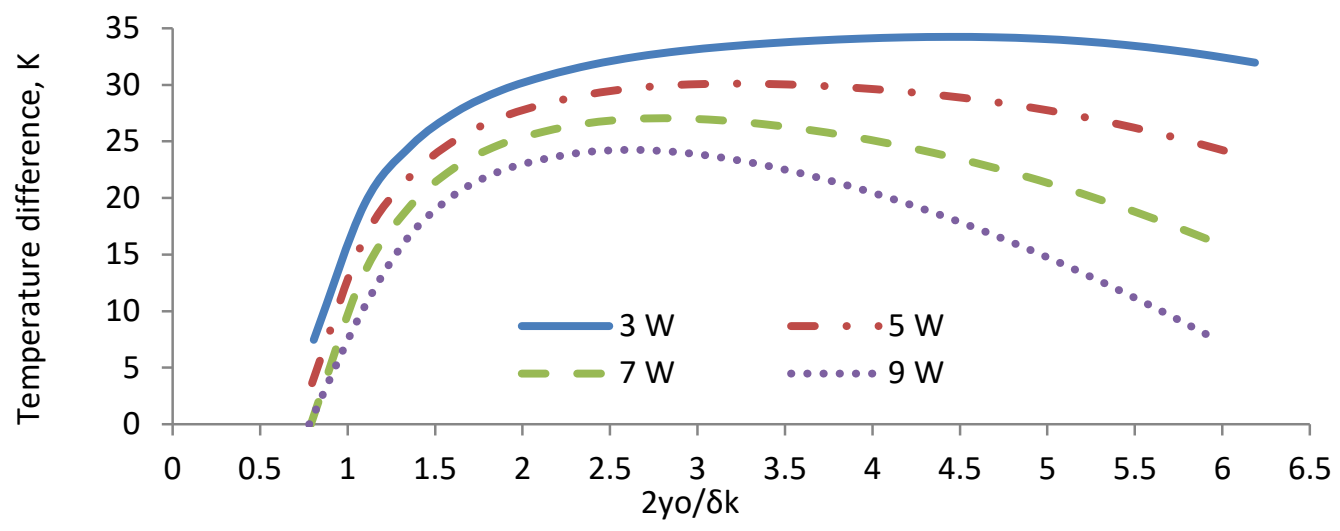

Fig. 8. The temperature differences vs. $2 y_{0} / \delta_{\mathrm{k}}$ at different cooling loads

\subsection{Stack Centre Position}

For different cooling load, the maximum temperature difference approximately equals to $8 \mathrm{~cm}$ as shown in Figure 9.

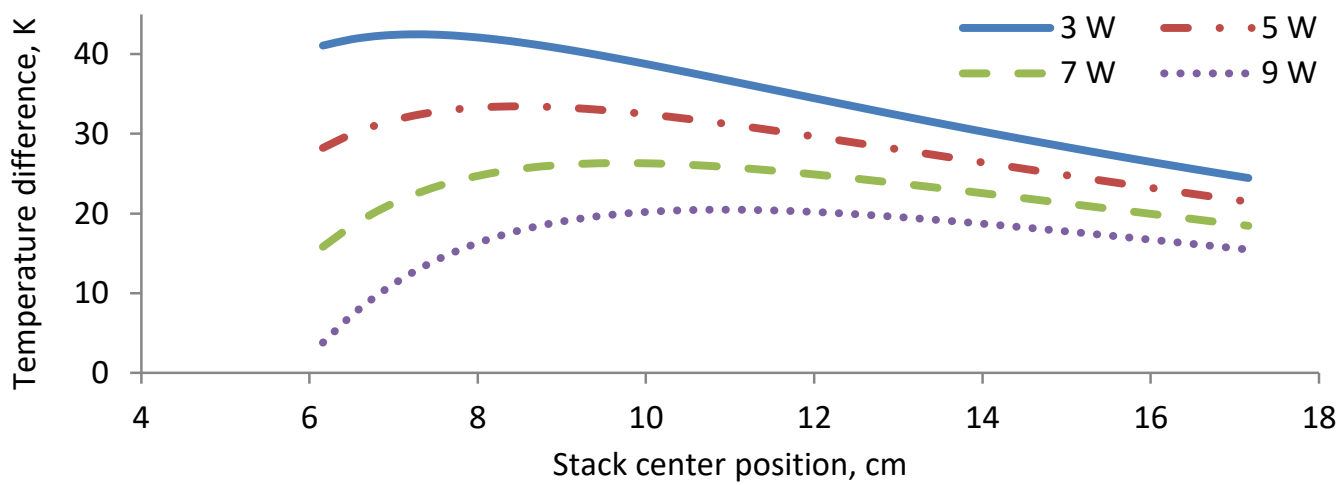

Fig. 9. The temperature differences vs. Stack centre position at different cooling loads

\subsection{Stack Length Analysis}

Increasing the stack length means that a larger number of the working gas molecules will interact with the stack plates. Thus, this enhances the temperature difference across the stack as shown in Figure 10.

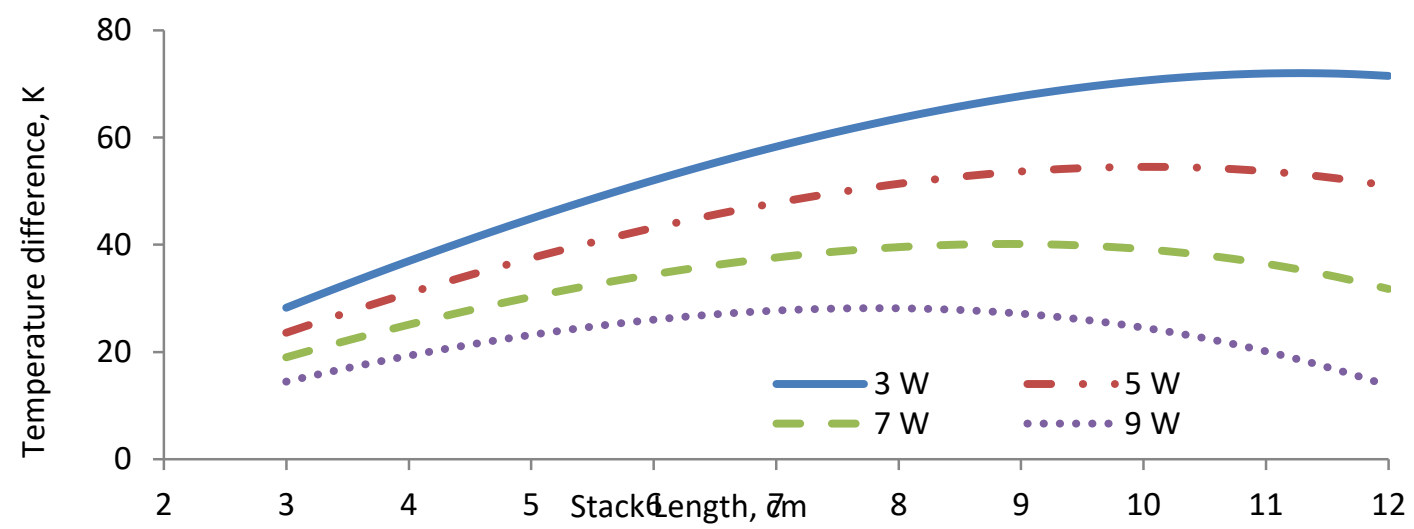

Fig. 10. The temperature difference variation with change in stack length at different cooling loads 


\section{Study Validation}

A validation model with Tejani [1] experimental work was performed as shown in Figure 11 for a driver ratio of $1.4 \%$, and a good agreement was obtained and thus current results using DeltaEC can be experimentally valid.

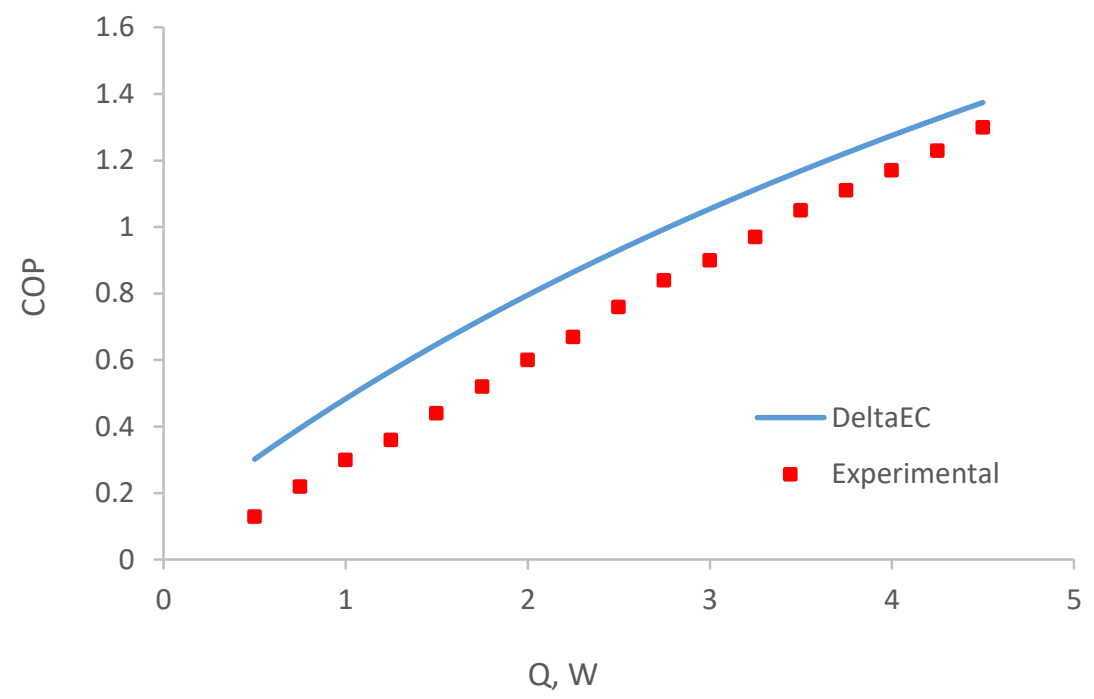

Fig. 11. Cooling load effect on the performance at $D=1.4 \%$ as obtained by Tijani [1] and DeltaEC

\section{Conclusions}

A thermoacoustic heat pump was designed and simulated using DeltaEC simulation program. The operating conditions and geometric parameters were changed with the incremental feature in the program to show the effect on the temperature difference across the stack. The first resonance harmonics had higher temperature difference and lower consumed acoustic power. Increasing the mean pressure decreases the temperature difference. However, increasing the amplitude pressure increases the temperature difference. The increase of the stack length also increases the temperature difference but this also could make the power consumption higher and thus leading to lower performance. This study is of great importance for the design considerations of thermoacoustic refrigerators.

\section{Acknowledgement}

Authors would like to thanks Universiti Teknologi Malaysia, Ministry of Higher Education of Malaysia for supporting this research. The research is supported by Fundamental Research Grant Scheme (FRGS-MRSA) no. 5F273 and Science and Technology Research Partnership for Sustainable Development (SATREPS) no. 4L891.

\section{References}

[1] Tijani, Moulay El Hassan. Loudspeaker-driven thermo-acoustic refrigeration. Eindhoven, Netherlands: Technische Universiteit Eindhoven, 2001.

[2] Wetzel, Martin, and Cila Herman. "Design optimization of thermoacoustic refrigerators." International Journal of Refrigeration 20, no. 1 (1997): 3-21. https://doi.org/10.1016/S0140-7007(96)00064-3

[3] Babaei, Hadi, and Kamran Siddiqui. "Design and optimization of thermoacoustic devices." Energy Conversion and Management 49, no. 12 (2008): 3585-3598. https://doi.org/10.1016/j.enconman.2008.07.002 
[4] Tijani, M. E. H., J. C. H. Zeegers, and A. T. A. M. De Waele. "Construction and performance of a thermoacoustic refrigerator." Cryogenics 42, no. 1 (2002): 59-66. https://doi.org/10.1016/S0011-2275(01)00180-1

[5] Alamir, Mahmoud A. "Experimental study of the stack geometric parameters effect on the resonance frequency of a standing wave thermoacoustic refrigerator." International Journal of Green Energy 16, no. 8 (2019): 639-651. https://doi.org/10.1080/15435075.2019.1602533

[6] Elnegiry, E. A., H. R. Eltahan, and M. A. Alamir. "Optimizing the performance of a standing wave loudspeaker driven thermoacoustic heat pump." International Journal of Scientific and Engineering Research 7 (2016): 460-465. https://doi.org/10.14299/ijser.2016.09.004

[7] Alamir, Mahmoud A. "Optimising the performance of a standing wave loudspeaker driven thermoacoustic heat pump." Master thesis, Mansoura University, Egypt. 2017. https://doi.org/10.13140/RG.2.2.24167.29609

[8] Alamir, Mahmoud A., and Ahmed A. Elamer. "A compromise between the temperature difference and performance in a standing wave thermoacoustic refrigerator." International Journal of Ambient Energy 41, no. 13 (2020): 14411453. https://doi.org/10.1080/01430750.2018.1517673

[9] Alamir, Mahmoud A. "Experimental study of the temperature variations in a standing wave loudspeaker driven thermoacoustic refrigerator." Thermal Science and Engineering Progress 17 (2020): 100361. https://doi.org/10.1016/j.tsep.2019.100361

[10] DeltaEC. “Design Environment for Low-amplitude ThermoAcoustic Energy Conversion; Version-6.0." LANL, 2007. www.lanl.gov/thermoacoustics.

[11] Arafa, N. M., A. H. Ibrahim, and E. E. Khalil. "Sensitivity analysis of a standing-wave thermoacoustic engine." In 9th Annual International Energy Conversion Engineering Conference, vol. 31. 2011.

[12] Jamaluddin, Mohd Syahmiyadiy, Md Mizanur Rahman, Mohd Faizal Hasan, Aminuddin Saat, and Mazlan Abd Wahid. "Performance evaluation of a small-scale solar driven refrigeration system." Journal of Advanced Research in Fluid Mechanics and Thermal Sciences 36, no. 1 (2017): 10-20.

[13] Saengsikhiao, Piyanut, Juntakan Taweekun, Kittinan Maliwan, Somchai Sae-ung, and Thanansak Theppaya. "Improving Energy Efficiency in the Supermarket by Retrofitting Low E Glass Doors for Open Refrigerated." Journal of Advanced Research in Applied Sciences and Engineering Technology 20, no. 1 (2020):11-17.

[14] Mohammad, Roslina, Foad Sharifi, D. Sharifi, N. Othman, and Zuritah A. Kadir. "Optimization of Heat Exchanger Network in Olefin Unit of Oil Refinery." Journal of Advanced Research in Fluid Mechanics and Thermal Sciences 13, no. 1 (2015): 1-16.

[15] Belaid, Kheira Nehar, and Omar Hireche. "Influence of heat exchangers blockage ratio on the performance of thermoacoustic refrigerator." International Journal of Heat and Mass Transfer 127 (2018): 834-842. https://doi.org/10.1016/j.ijheatmasstransfer.2018.05.144

[16] Alamir, Mahmoud A., Kristy L. Hansen, and Branko Zajamsek. "The effect of wind farm noise on human response: An analysis of listening test methodologies." In Proceedings of ACOUSTICS, vol. 7, no. 9. Adelaide, Australia, 2018.

[17] Mohammad, Roslina, Foad Sharifi, D. Sharifi, Norazli Othman, and Zuritah A. Kadir. "Design of heat exchanger network in olefin unit of oil refinery." Journal of Advanced Research in Fluid Mechanics and Thermal Sciences 12, no. 1 (2015): 21-34.

[18] Hayder, G., and P. Puniyarasen. "Identification and evaluation of wastes from biodiesel production process." Journal of Advanced Research in Applied Sciences and Engineering Technology 3, no. 1 (2016): 21-29.

[19] Alamir, Mahmoud A., Kristy L. Hansen, Branko Zajamsek, and Peter Catcheside. "Subjective responses to wind farm noise: A review of laboratory listening test methods." Renewable and Sustainable Energy Reviews 114 (2019): 109317. https://doi.org/10.1016/i.rser.2019.109317

[20] Ismail, H., A. A. Aziz, R. A. Rasih, N. Jenal, Z. Michael, and Azmi Roslan. "Performance of Organic Rankine Cycle Using Biomass as Source of Fuel." Journal of Advanced Research in Applied Sciences and Engineering Technology 4, no. 1 (2016): 29-46.

[21] Berrabah, H. M., N. Z. Sekrane, and B. E. Adda. "Comparative study of sound wave propagation in single-walled carbon nanotubes using nonlocal elasticity for two materials (Al) and (Ni)." Journal of Advanced Research in Fluid Mechanics and Thermal Sciences 18, no. 1 (2016): 20-34.

[22] Kwong, Tang Hing, Flora Anak Albert Daud, and Chai Teck Jung. "Sustainable Green Concrete by using Biomass Aggregate." Journal of Advanced Research in Applied Sciences and Engineering Technology 18, no. 1 (2020): $31-37$.

[23] Alamir, Mahmoud A., Aws AlHares, Kristy L. Hansen, and Ahmed Elamer. "The effect of age, gender and noise sensitivity on the liking of food in the presence of background noise." Food Quality and Preference (2020): 103950. https://doi.org/10.1016/j.foodqual.2020.103950

[24] Hailegiorgis, Sintayehu Mekuria, Saleem Nawaz Khan, Nur Hanis H. Abdolah, Muhammad Ayoub, and Aklilu Tesfamichael. "Investigation of Carbon Dioxide Solubility in Aqueous N-methyldiethanolamine (MDEA)-1-butyl-3methylimidazolium acetate ([bmim][Ac]) Hybrid Solvent." Journal of Advanced Research in Fluid Mechanics and Thermal Sciences 42, no. 1 (2018): 65-71. 
[25] Ismail, Zakaria, Nik Azmi Nik Mahmood, Noor Azrimi Umor, and Syed Anuar Faua'ad Syed. "Submerged Bed Biofilms Reactor (SBBR) for Industrial Wastewater Treatment." Journal of Advanced Research in Applied Sciences and Engineering Technology 17, no. 1 (2019): 45-53.

[26] Alamir, Mahmoud A., and Kristy Hansen. "The effect of type and level of background noise on food liking: A laboratory non-focused listening test." Applied Acoustics $172 \quad$ (2021): 107600. https://doi.org/10.1016/i.apacoust.2020.107600

[27] Alamir, Mahmoud A. "An artificial neural network model for predicting the performance of thermoacoustic refrigerators." International Journal of Heat and Mass Transfer 164 (2021): 120551. https://doi.org/10.1016/j.ijheatmasstransfer.2020.120551 